\title{
Learning CAD at university through summaries of the rules of design intent
}

\author{
Basilio Ramos Barbero, Carlos Melgosa Pedrosa, Raúl Zamora Samperio \\ E-mail address: bramos@ubu.es
}

Graphic Expression Department, Escuela Politécnica Superior, Universidad de Burgos, Avda. Cantabria s/n. 09006 Burgos, Spain.

\begin{abstract}
The ease with which 3D CAD models may be modified and reused are two key aspects that improve the design-intent variable and that can significantly shorten the development timelines of a product. A set of rules are gathered from various authors that take different 3D modelling strategies into account. These rules are then applied to CAD strategic-knowledge learning methodology and included in 3D CAD modelling exercises for students following the degree in mechanical engineering at the University of Burgos (Spain). The experiment was conducted in two groups with a total of 75 students. The designintent rules were introduced in the different exercises that the teacher explained in both the theoretical and the practical classes. In addition, a summary of the different design rules in each of the practical exercises was explained in the practical classes in only one of the groups. The experimental results, reported in this paper, tested the influence of these summaries on overall improvements in 3D modelling and on the design-intent variable, which is subdivided into four sections: skeleton, structures, alterations and constraints. The use of the summaries of the design intent rules led to statistically significant improvements in 3D modelling in the experimental group, in comparison with the group of students to whom those summaries were not explained.
\end{abstract}

\section{KEYWORDS:}

Strategic knowledge; 3D CAD learning; reuse and alteration of the CAD model; design intent; 3D design rules.

\section{INTRODUCTION}

The Model-Based Enterprise (MBE) concept emerged in the United States at around 2010 (Contero 2015). At the centre of the MBE concept is the reuse of CAD models (Camba et al. 2014a). This reuse is based on the idea that it should be possible to alter 3D CAD models throughout the product life-cycle, so that these models may in addition form the basis of new models that may subsequently be altered. If CAD models are easy to reuse, the benefits that they can contribute are much greater. For this to happen, the methodologies should be easily understandable to other people who should be able to alter the models easily, a situation that is not always fulfilled. In this context, a critical aspect of the reuse of CAD models is the identification and understanding of the design intent of the model, which is generally implicitly expressed in the CAD model.

In this work, “design intent" or "'geometric modelling intent"' will be used indistinctly to express the reasons that motivate a designer to perform some specific CAD modelling actions. It begins with the parts and their views and dimensions. The idea is to define the modelling process of the parts, taking into account the design intention in CAD. Design intent also expresses the manner in which the designer expects the geometric model to behave when it is modified (Alducin-Quintero et al. 2012). Unfortunately, the alteration of a CAD model can in many cases be difficult or even impossible (Salehi and McMahon 2009a). According to Yang and Han (2006), a third to a half of all quality problems arise either from poor design skills or from the inexperience of designers.

Cutting-edge firms are developing techniques and technologies to exploit the reuse of designs. It is well known that reuse has competitive added-value for firms, as it shortens their design lead times and as a consequence their products are launched more quickly on the markets. Reuse and ease of alteration of their 3D models is therefore a key issue. Jackson and Buxton (2007) demonstrated through a survey, that the reuse of $3 \mathrm{D}$ models is difficult to carry out in many firms: because the alterations require in-depth knowledge of CAD (57\%), because the CAD models are inflexible and fail after the changes (48\%), and because only the designers that made the models can successfully introduce the changes afterwards (40\%). 
In view of the above, the question arises of how CAD is learnt. In a study divided into two parts, Hartman (2004, 2005) sought to determine how expert designers in firms achieved their existing knowledge levels of CAD and demonstrated how new CAD students need practices where they design and alter the models, so that they may be trained in the design of complex models. On this point, Mandorli and Otto (2013) affirmed that present-day university courses should impart more strategic knowledge and understanding to enable students to use CAD systems as knowledge-intensive design and communication tools, to properly develop design intent and to be able to convey it.

Teaching-learning of CAD on mechanical engineering degree courses at university is evolving very quickly. At present, the 3D CAD methodology is principally based on: parametric design, feature modelling, tree use and the parent/child dependency relation of the features. According to Otey et al. (2014), there is a consensus that modelling tools and strategies greatly influence design intent. There is also agreement on the convenience of introducing design intent through proper modelling strategies when learners are beginning to model. Strategies and approaches aimed at adding design intent into CAD models to enhance their quality, together with metrics aimed at evaluating their efficiency, are now receiving some attention.

It is known that learning time is limited and CAD tools increasingly offer greater possibilities and more time is needed to exploit them to the full, although it is not available to us. Hence, Chester (2007) proposed CAD learning that stimulates skills related to the selection of the most appropriate combination of design principles and rules to resolve the problems. Strategic knowledge learning should be used instead of learning by commands. Strategic knowledge is related to knowledge of alternative methods by which a task may be carried out and what the correct process is for the task to be done.

Barbero and García ( 2011) believed that learning should take place by strategic knowledge and using the problem resolution method at the design stage and the simulation of simple mechanisms, starting with the modelling of each part, through to the assembly, the simulation, the analysis and the parametric alteration of the component parts of the mechanism, and finishing with confirmation of the design intention through parametrical alterations. An efficient form of learning in CAD is to design a simple mechanism from the beginning to the end, as a practical exercise.

In the completion of practical exercises in CAD, students learn the theoretical concepts, identify the correct paths for modelling and obtain strategic 3D design rules. This constructivist methodology, of exercise-based learning, allows the generalization of theoretical and practical concepts of 3D design through short summaries or statements that contain the design intention rules, which teachers can present in the practical classes, so that their students take them into account in subsequent CAD exercises.

It was therefore decided to conduct an experiment to establish whether the summaries of the design rules currently in use improved student learning of design intention on the Graphic Engineering module in Mechanical Engineering at the University of Burgos (Spain).

Our work therefore had the objective of confirming whether a summary of the design intent rules, presented at the start of each practical class, significantly improved the learning of CAD that incorporates design intention; and in consequence the rules that are used should be taken into account in the future.

\section{RELATED WORK}

It is worth noting, to focus the work, that graphic engineering at present covers such various fields as: visualization, geometry, technical drawing, CAD 2D and 3D, and inverse engineering, among others. This study centres on the field of CAD 3D, and more concretely, on the way in which parts should be modelled with solids and surfaces so that they can be easily modified, complying with the requirements set by CAD and therefore with the design intention in CAD.

\subsection{Design Intention in CAD and reutilization of the models}

Although there is no official definition of design intent in CAD, many authors have sought to define this term. 
Design intent for Otey et al. (2014) is commonly defined as the anticipated or expected behaviour of a CAD model after it undergoes a modification. For example, if two holes are coaxial and the diameter or position of one of the holes is modified, the other will continue to be coaxial. The introduction of a geometric constraint of concentricity between the centres of the circles that define those holes is necessary to comply with this requirement.

Rynne and Gaughran (2008), defined design intent as a description of how an object is modelled and how it should perform once it is altered.

Kimura and Suzuki (1989) defined design intent as the way in which CAD designers should produce models so that manufacturers may understand the design process with a view to guaranteeing the manufacture of a product. This definition includes the idea that thought should be given to how the product will be manufactured and that the modelling process should be understandable to the manufacturers at the design stage.

Iyer and Mills (2006) proposed their own definition: "Design intent contained in legacy CAD is insight into the design variables (design objectives, constraints, alternatives, evolution, guidelines, manufacturing instructions and standards) implicit in the structural, semantic and practical relationships between geometric, material, dimensional and textual entities present in the CAD representation’’.

The common point for acceptable design that can be discerned in these and in other definitions of design intent by other authors not included in this work is that, for design intent to be acceptable (and this is the key point), the models should be reusable. For this purpose, the parts should be easily identifiable, the models easily altered and the results of the alterations should be as expected. On this point, Drury et al. (2013) made it clear that CAD models may be altered and reused, if they are easy to use, and if they are effective (usability and efficacy).

Design intent is expressed throughout the structure of the model (sketches, constraints, equations, operations, tree, skeleton, features, etc.). Design intent is said to be maintained when it is flexible and robust. It may be said that a design is flexible when changes can be made to its structure. A 3D design is said to be robust, if it can offer the expected results when subjected to changes to part of its structure (tree, skeleton, operations, features, equations, etc.) at any time.

As commented in the introduction, certain rules are necessary that refer to the reuse of CAD designs, for example:

- $\quad$ Bodein et al. (2013) proposed to dedicate time to think of the design process and to define the road map of the modelling in the first phases of modelling.

- $\quad$ Bodein et al. (2013) reported that some authors proposed top-down, bottom-up and in context design methodologies; others proposed methodologies, bearing in mind the alterations and needs of clients (using functional geometry); others used parametric design methodologies associating the parameters with geometric entities; others employed parametric design in CAD, thinking of component standardization; and others proposed thinking about the manufacturing process in modelling, for which purpose the manufacturing operations in the tree have to be identified in an explicit way, the different manufacturing operations have to be independent and manufacturing operations libraries have to be created.

- Define an acceptable operations tree. The operations tree or historic tree of the model implicitly offers a representation of the design intent, but not all the information on the design intent is visible and easily understandable from the historic tree (for example, the concentricity constraint in a sketch is visible in the tree, but it is difficult and it takes time to know the physical elements between which this relation exists).

- $\quad$ The use of geometric constraints that capture the design intent (Ault 1999).

- $\quad$ The preliminary task is to identify acceptable functional parameters for the requirements and to construct the appropriate parametric structure (Bodein et al. 2014; Salehi and McMahon 2009b, 2011), to obtain a valid and functional CAD model.

\subsection{CAD Learning}

The use of some of these rules and many others that are not included here will depend on the complexity of the 3D model and on other questions, such as for example, the type of firm where they are used. To do so, for Chester (2007) learning of CAD 3D should be through strategic knowledge-based learning 
methodology instead of a command methodology. Command knowledge is referred to as knowledge of the commands (algorithms or tools) and the procedures to use those tools within CAD software, while strategic knowledge is concerned with knowledge of the alternative methods to achieve a specific task and the process by which a choice may be made.

Chester (2007) produced evidence that learning based on strategic knowledge is more effective without it having to be combined with learning to specify command execution procedure, and that it is more effective in students who have less prior knowledge of CAD. He also stressed three key skills that to some extent influenced whether his students would go on to become CAD experts through the strategic knowledge-based learning method: analysis, metacognition and mental imagery. This strategic knowledge should be learnt through training.

"Metacognition" (Herrera and Marcelo 2006) is understood as the capability that people have to selfregulate their own learning, in other words, to plan what strategies have to be used in each (learning) situation, to apply them, to control the process, to evaluate it so as to detect possible weak points, and in consequence... to transfer all of it to a new action or learning situation. Metacognition has four identifying characteristics (Burón Orjas 1993): 1) to know the objective to be reached; 2) to be able to choose between possible strategies to achieve the objectives; 3) self-observation of the process of knowledge preparation, to find out whether the selected strategies are appropriate; and, 4) evaluation of the results to know how far the objectives have been achieved.

We should keep in mind that students in the classroom follow different paths to design the same part in CAD, as there is no general CAD methodology. They produce the same part, by complying with the definition of the problem (views and dimensions), but in different ways. One of the most highly valued objectives of education is to achieve autonomous, independent and self-regulated learning, where the student acquires a learning-to-learn capability and learns by doing. In this learning-by-doing methodology, which is the basis of constructivism, the command options are not explained (unlike in the methodology by commands). The idea is that the student selects the most appropriate command and its option from among those that are possible, on the basis of previous experience. From that point of view, knowledge is acquired through a sort of knowledge called strategic knowledge, which is based on a "controlled understanding” strategy (Córdova 2009). This approach leads on to strategic learning, understood as the set of activities that assists students to control, to plan, and to organize their own learning process, and to evaluate its efficiency and effectiveness. This strategic learning also implies a metacognitive activity, which is understood as the students' abilities to reflect on their own learning process and is done in three phases: beforehand, during and afterwards. Beforehand, the goals are planned, as well as the relevant learning strategies and resources. During the completion of the task, supervision and monitoring is done, reviewing the way in which the problem was solved. And afterwards, the achievements are evaluated that will permit modification and consolidation of the strategies in use.

Students may consider that they control their cognitive acts and their learning, and that effective learning depends on how well, or badly, they apply their strategies and their knowledge, but above all, that they are the ones who can improve, by deciding on which components they have employed ineffectively, to be able to improve in the future (Ugartetxea 2001). In this way, the students create their 3D modelling strategy, for example, a strategic rule is to complete the rounding of an edge before using the shell feature.

One way of testing whether an appropriate strategy was employed is to modify the CAD models. The design alterations contribute two fundamental aspects to the learning processes of engineering students (Barbero and García 2011):

1.- From the point of view of design intention and design method. It allows one or various paths to resolve a CAD problem and to compare which of the methods is the most suitable and which best maintains the design intent.

2.- From the pedagogic point of view. Any error or inconsistency is not a failure, but something natural and useful to find the optimum modelling path with other CAD tools, and it serves to structure the students' minds around design methods and to define a series of general norms or general strategic rules on design knowledge.

In consequence, following a review of the bibliography, it appears that 3D CAD learning is more efficient through a strategic knowledge learning methodology, where the different CAD concepts and training in the development of the metacognitive skills are learnt through exercises. These CAD exercises should be 
selected in such a way that their solution requires the application of a set of rules aimed at compliance with design intent. The design rules to apply to each exercise are summaries that can be presented to students so that they consolidate their concepts of CAD and improve their learning. We believe that presenting these summaries or sets of CAD design rules can significantly improve CAD learning.

\section{METODOLOGY AND EXPERIMENTATION IN THE CAD LABORATORY}

The principal objectives of CAD learning in graphic engineering are (Bi 2013; Barbero and García 2011; Ye et al. 2004):

- To know the methodology and design process of a part or component in CAD 3D.

- To know how to structure the design of an assembly and its components in 3D, in such a way that its design is flexible and robust.

- To know how to carry out computer 3D modelling of parts, using modelling tools to model solids and surfaces.

- To know how to set up parts in assemblies, taking into account the functioning of the device.

- To know how to detect and correct both assembly errors and functional errors in the different components of each device.

The main sections of the theoretical concepts are: design of the parts with solids, creation of design tables and parts catalogues, design by surfaces, creation and management of assemblies, functional simulation, and simulation of their assembly.

The principal rules to apply to 3D CAD learning by means of strategic learning, covered in some of the following works (Bodein et al. 2013, 2014; Camba et al. 2014a; Hartman 2004, 2005; Kimura and Suzuki 1989; Rynne and Gaughran 2008; Zhang and Luo 2009), are:

- To dedicate time to thinking before starting to work. The key is to think of and to focus on the development process of the product at all times. Thought should be given to the origin of the parts; to their patterns and symmetrical properties; to basic operations like extrude, sweep and multisection by which the real pieces for each part are obtained; in the necessary curves and sketches that should be used to create the basic parts, etc.

- To place geometrical constraints on the sketches and the models. One proposal is to use explicit references to the knowledge that is introduced in the CAD model as constraints. The constraints are very useful in complex designs and give flexibility to those designs. Explicitly defined points, lines, planes, curves and surfaces should be used for the constraints in the sketches. The sketches should have the lowest possible number of degrees of freedom.

- To use new reference plans, initially coinciding with the original plans of the model so that they can subsequently be altered, if necessary. This is a rule for positioning the elements in the assemblies.

- To identify and to understand the design intent in the models. The parts are divided into their pieces paying attention to such different criteria as: the CAD modelling process, the manufacturing process and the functioning of the part.

- Label each part with an acceptable name. The names should be given taking into account the design intent and the dimensions of each feature, and not with the name of the operation.

- $\quad$ Use the skeleton in the parts and in the devices.

- Think of the reutilization of the CAD models, for which purpose alterations are introduced into the models and the parts should be divided into their components. Place the features, which you expect to be altered or eliminated at the last levels of each branch of the tree. Hence, the chamfer and fillet features will be the last ones.

- Use Boolean operations. The use of Boolean operations assists the breakdown of the piece into its component parts.

- Make use of bottom-up and top-down design methodologies at the level of the piece and the mechanisms. In the design, both methodologies are jointly used (methodology in context) in accordance with the initial data used for the design of the model.

- Be familiar with and employ CAD history or operation trees with different structures. Camba et al. (2014b) proposed the use of three types of tree structures (horizontal, explicit references and resilient), each with its advantages and disadvantages. The resilient method was proposed by Gebhard (2013) who divided the tree into seven parts, grouping different elements in each one of them. These parts are: 1-Reference elements, 2- Constructive elements 3-Core (features that define the general form of the model), 4- Detail, 5-Modify, and 6-Quarantine (features that 
should not be parents). An effort should be made so that the number of parent-child dependency relations is small. The dependent features (child nodes) should also be positioned as close as possible to their parent nodes and especially those that will be altered.

- To identify and to define the functional parameters that define the different requirements and place them at the start of the tree. At the same time, the dependent parameters are related through formulas to the functional parameters.

- Parameterize the models through design tables, subsequently creating the libraries for them.

A specific rule, that the authors employ when using CATIA software, is that PartBody (the initial node of each piece) should not initially be used, so as to be able to place the finished part in the PartBody node as the final operation, by means of an assemble operation. In this way, it is certain that the finished piece is always found in PartBody.

Two groups were set up to test whether the summaries of the design rules presented to the students improved CAD learning and their design intent: one was an experimental group (E) and the other was a control group (C), with the sole difference that the professor in group E, and solely in the practices, presented the summary of the 3D design rules. In the theory classes, the teacher proposed a set of exercises, in both groups, different from those of the practices, so as to guide the students in CAD learning and to identify the strategies to follow in the different exercises, in order to comply with the design intent.

Three examples of summaries are shown below, taken from the various summaries that were only used with group $\mathrm{E}$ and that took the aforementioned 3D CAD learning rules into account.

First example of a summary (Fig. 1). The thinking process is explained that the students have to follow before they complete the modelling process of a piece. Here, the input elements are the product development process, the design rules and the CAD tools and the output elements are the skeleton and the structure of the tree. To do so, thought has to go into the design intent and in consequence the models should be flexible and robust.

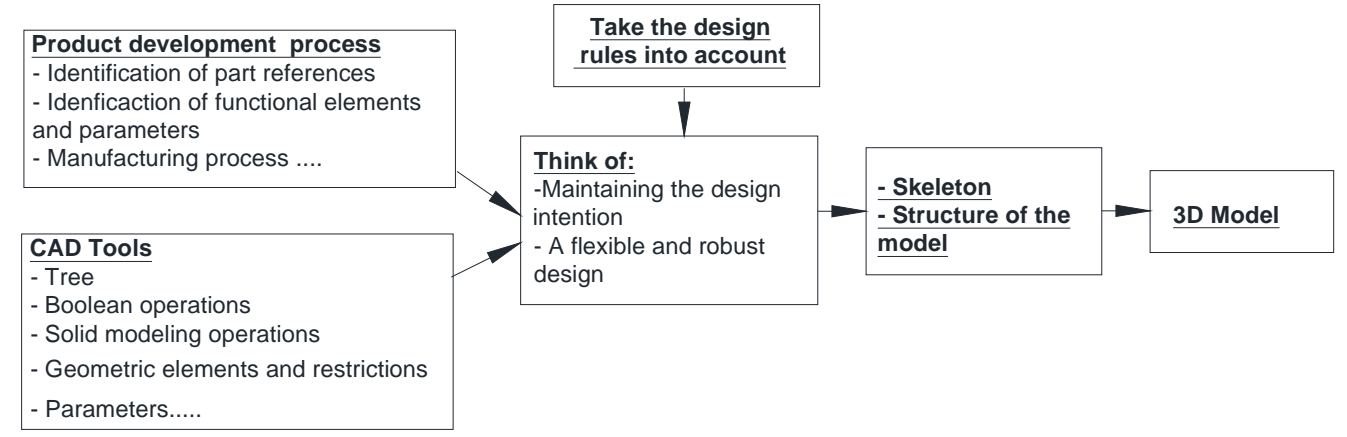

Fig. 1 The 3D modelling process of a piece

Second example of a summary. The eight shared steps of the modelling method proposed by Hartman (2005) are explained: 1) Determine sketching plane, 2) Sketch profile, 3) Add constraints/relations, 4) Add dimensions, 5) Apply feature form, 6) Repeat steps 1-5 to add major features, 7) Add materialremoval features (holes, cuts, etc.), 8) Add finishing features (round, fillets, etc.).

Third example of a summary. In the elbow exercise, eight alterations were proposed to groups E and C after its modelling and three of the alterations appear in figure 2. With the alterations in this exercise, the students become aware of the importance of thinking of the way in which the 3D models may be modified. 


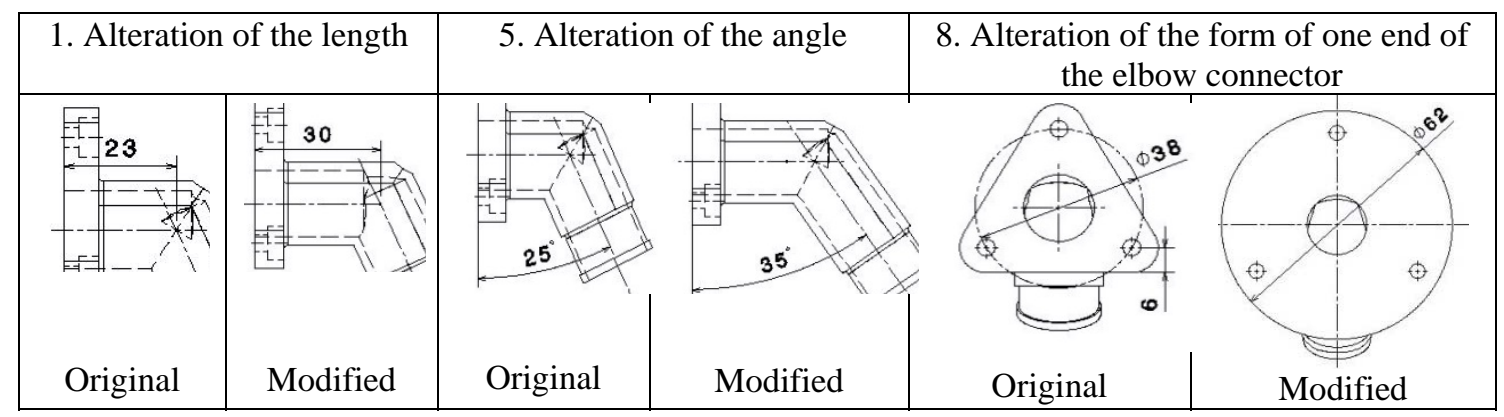

Fig. 2 Three of the eight alterations of the elbow connector

Subsequently, the separate parts of the elbow connector were explained in the summary that defines its skeleton and structure presented to group E (Fig.3).
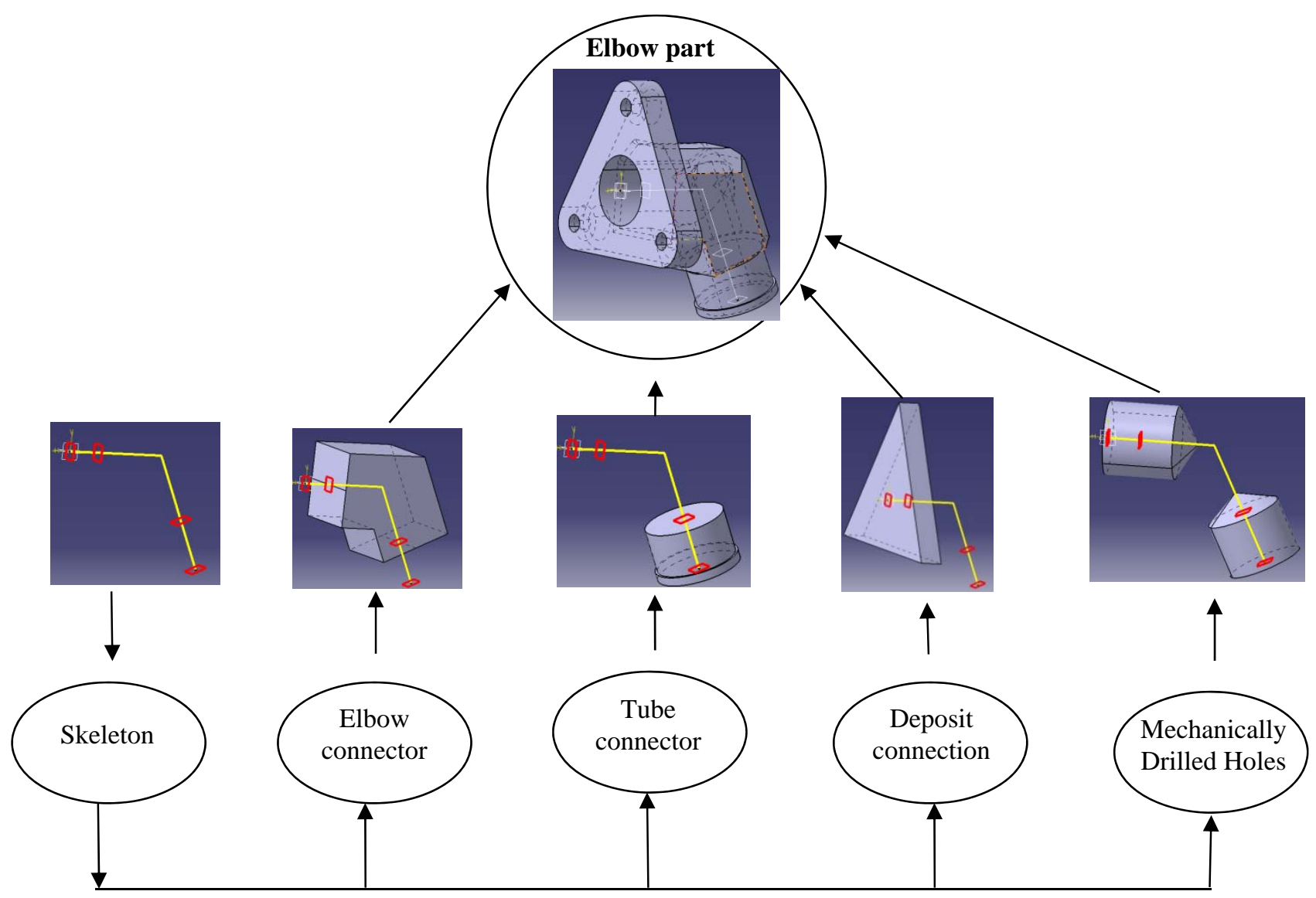

Fig. 3 Separate parts of the elbow connector

Given that there are many paths that lead to the result of a CAD model, that CAD tools rapidly evolve, that learning needs in relation to CAD are increasingly greater, and that the available time is very limited, the learning of design rules in CAD 3D is proposed through a set of exercises, selecting each one for the purpose of learning the different concepts and rules. Nine exercises, shown in figure 4, were used in the experiments in the practical classes. The students also designed a complete mechanism (office chair) that constituted their end-of-course assignment. This exercise was not included in the investigation. Ye et al. (2004) through a survey with different CAD experts came to the conclusion the most important aspect is practice to improve CAD learning. Nothing can be more important than to carry out the design of small mechanisms: in our case, an office chair.

The students learn about the contents through these exercises for the design of the part and its simulation and alteration; in other words, a response is given to the question: What do they learn? They learn about CAD strategic knowledge through the methodology of completing these exercises, so a response is given to the question: How do they learn? 


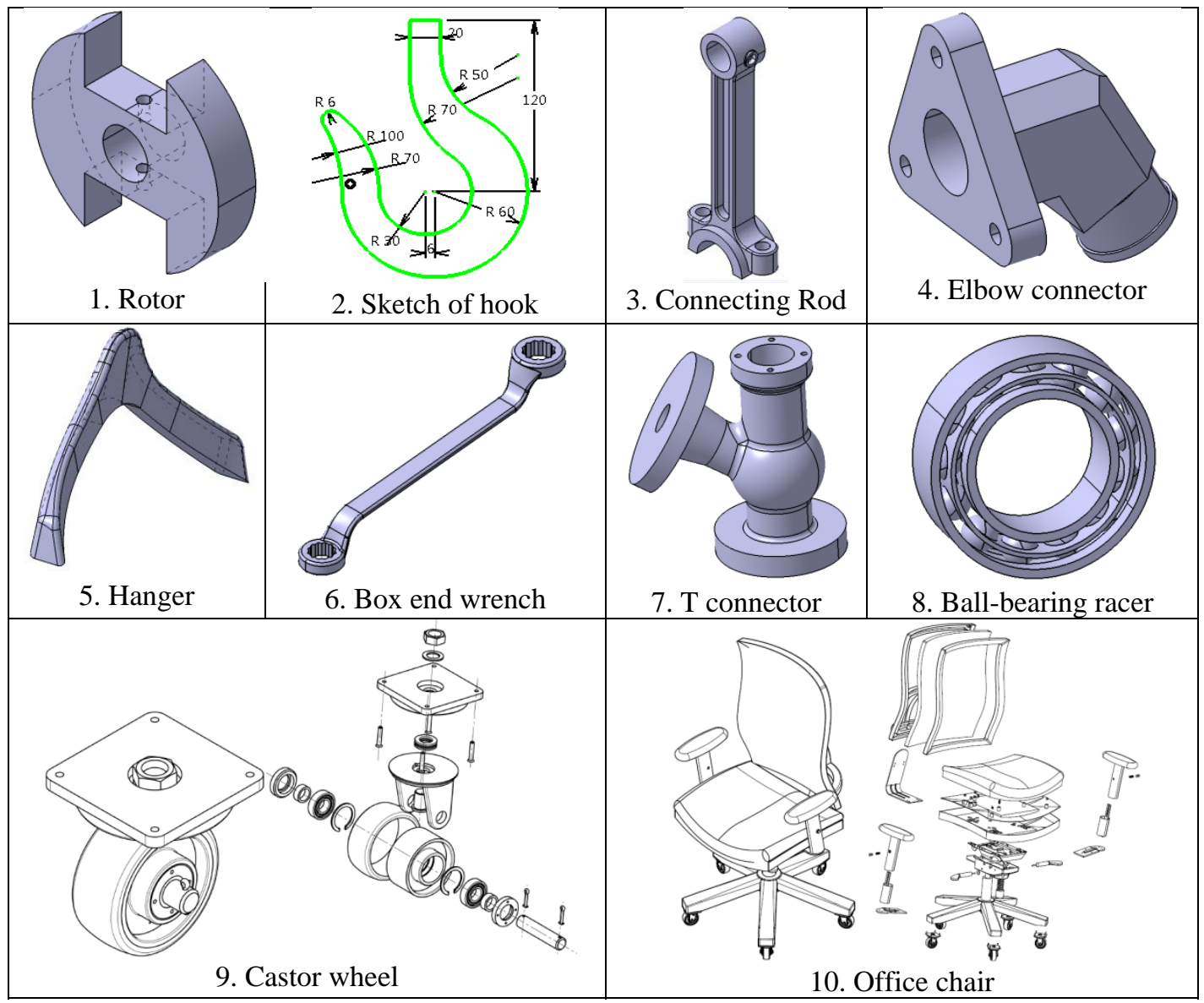

Fig. 4 Practical exercises completed

Once completed, the different exercises were corrected and evaluated by the teachers (each exercise for all groups by a single teacher), taking account of the two edges in the two groups: on the one hand, taking account of the degree of similarity of the 3D models from each student with the original models in relation to their dimensions and forms; and on the other hand, compliance with the design intent, for which purpose various alterations in the 3D models were completed and tests established whether these alterations were properly reflected in the exercises of the students.

In an initial study, the first nine exercises (see figure 4) were jointly evaluated on the two edges (dimensions and forms and design intents), after which the applied theory was included. Each of the exercises and the applied theory were corrected and marked out of ten points, and the variable "Average Exercises" was defined as the average of them all (see table 2).

In a second study, only the design intent was evaluated. The evaluation of design intent by the teachers was done in four steps:

1- Testing whether the geometric and dimensional constraints in the sketches are correct.

2- Testing whether the model has a skeleton and contains the fundamental design parameters.

3- Testing the structure of the tree:

- $\quad$ The acceptable names of the sketches, features, Boolean operators, etc.

- Which parts of the tree structure contain the parts of design process and/or manufacturing process?

4- Modifying the fundamental parameters of the models and the form of some of their parts and subsequently testing that the result is as expected.

A theoretical examination with two parts was given at the end of the course on graphic engineering: one on theoretical concepts ("theory") and another on applied theory. "Theory", given that it only evaluated purely theoretical questions, the solutions to which only required memory, while design intent skills had no influence, for which reason it was not taken into account in any of the two studies. In the applied theory, questions were asked in relation to design intent. Specifically, students were asked to identify the 
skeleton, the parts of a piece and the operation that should be employed to obtain a part from a piece. This applied theory was taken into account in the two studies.

In the second part of the study, the partial scores obtained in the different exercises were extracted as well as the scores in the applied theory according to the four parts taken into account in the evaluation criteria of design intent that is defined above. As a result, the design intent variables that under consideration were: skeletons, structures, alterations and sketch constraints. Two aspects were considered for the "Structures" variable: i) that the structure was created with a representative name ("Features name"), ii) and that the parts of the tree (Parts) had been properly created. (See table 4).

The four variables scored out of 10 . The two components of the variable "Structures" scored out of 3 in the case of "Features name" and out of 8 in the case of "Parts". "Total of Design Intent" was the sum of the four variables of design intent and scored out of a total of 40 .

The experiment was conducted from September 2014 to January 2015 with an initial population of 75 students (13 females) divided at random into two groups: one group of 40 students in a control group (C) and another group of 35 students in the experimental group (E). The only difference, as said, was that, for approximately 5 minutes, the teacher went over a short summary of the 3D design rules in the different practical classes of the experimental group.

It was confirmed that Groups $\mathrm{E}$ and $\mathrm{C}$ were statistically equivalent in relation to the four following variables that could have an influence on the results of the investigation: gender; previous knowledge of CAD, "CAD Knowledge"; previous knowledge of technical drawing; "TD marks"; and, spatial vision. Two variables, gender and previous knowledge of CAD were measured through direct questions in a survey; previous knowledge of technical drawing was measured from the average scores in the two Technical Drawing study modules that the students should have previously completed; and, the variable spatial vision was measured with the Mental Cutting Test (MCT) (CEEB 1939).

\section{RESULTS}

\subsection{First study (Average score of exercises)}

First of all, segmentation of the sample was performed in accordance with the four demographic variables mentioned in the preceding paragraph. To do so, two situations were considered, the whole sample together and divided into groups $\mathrm{E}$ and $\mathrm{C}$. The results of the segmentations are shown in table 1: the difference in means, the result of the t-student test of equality of means, and its significance. The column "Cut-off" indicates how the segmentation groups (A and D) were formed in relation to the different demographic variables.

As might be expected, the students with better spatial vision obtained better results in a significant way with regard to the variable "Average Exercises". Students with prior knowledge of CAD obtained better and significant results.

Table 1. Results of demographic segmentations with regard to "Average Exercises"

\begin{tabular}{|l|l|c|c|c||c|c|c|c|c|c|}
\hline \multicolumn{10}{|c|}{ Independent Samples Test } \\
\hline \multirow{2}{*}{ Variable } & \multicolumn{2}{|c|}{ Cut-off } & \multicolumn{3}{|c|}{ Full sample (A-D) } & \multicolumn{2}{|c|}{ Group A (E-C) } & \multicolumn{3}{c|}{ Group D (E-C) } \\
\cline { 3 - 11 } & & Dif. & t & Sig. & Dif. & t & Sig. & Dif. & t & Sig. \\
\hline Spatial vision & $\mathrm{A}>60 \%$; $<<=60 \%$ & 0.74 & 2.932 & $\mathbf{0 . 0 0 4}^{*}$ & 0.66 & 2.029 & $\mathbf{0 . 0 4 9}^{*}$ & 0.69 & 1.969 & $\mathbf{0 . 0 5 9}^{* *}$ \\
\hline TD marks & $\mathrm{A}>6 ; \mathrm{D}<=6$ & 0.54 & 1.601 & 0.114 & 0.36 & 0.372 & 0.717 & 0.67 & 2.658 & $\mathbf{0 . 0 1 0}^{*}$ \\
\hline CAD Knowledge & $\mathrm{A}=$ Yes; $\mathrm{D}=$ No & 0.49 & 1.768 & $\mathbf{0 . 0 8 1}^{* *}$ & 0.88 & 2.057 & $\mathbf{0 . 0 5 2}^{* *}$ & 0.31 & 0.984 & 0.330 \\
\hline Gender & $\mathrm{A}=$ Male; $\mathrm{D}=$ Female & 0.40 & 1.169 & 0.246 & 0.58 & 2.045 & $\mathbf{0 . 0 4 5}^{*}$ & 0.74 & 1.134 & 0.281 \\
\hline * Significant difference at a level of 0.05 \\
** Significant difference at a level of 0.1
\end{tabular}

When the sample divided between the experimentation and the control groups is considered and segmented according to the level of spatial vision, we may affirm that the results of the students with stronger spatial vision in group E were significative and better than those with stronger spatial vision from group C. Moreover, the results of the students with weaker spatial vision from group E were significative and better than those of group C that were significant (see table 1).

It may also be seen from this table that the difference between groups $\mathrm{E}$ and $\mathrm{C}$ was significant for students with a lower mark in TD and favoured Group E. With regard to previous knowledge of CAD, there was a 
significative difference between students from Group E who held previous knowledge of CAD and those from group $\mathrm{C}$ under the same conditions. There was no significative difference between women from Group E and those from Group C, although a significative difference did exist between the men from both groups.

In second place, the average values of each exercise are shown in table 2 alongside the standard error of the average in groups $\mathrm{C}$ and $\mathrm{E}$, and the result of the t-student test of equality of means, and its significance.

Previously, the assumptions of the validity of this test were verified, with the result that although the distribution of the scores for the Hook, Hanger, T-connector and Box-end Wrench exercises were not normal, as the size of the samples was between 15 and 40 and they were not strongly asymmetrical, the results of the t-test may be considered valid.

Table 2. Results of the CAD exercises

\begin{tabular}{|c|c|c|c|c|}
\hline \multicolumn{5}{|c|}{ Independent Samples Test } \\
\hline \multirow{3}{*}{ Exercises } & \multicolumn{2}{|c|}{ Experimental group or Control group } & \multicolumn{2}{|c|}{ t-test for Equality of Means } \\
\hline & $\mathbf{C}$ & $\mathbf{E}$ & \multirow[b]{2}{*}{ t } & \multirow[b]{2}{*}{ Sig. } \\
\hline & Mean (Std. Error Mean) & Mean (Std. Error Mean) & & \\
\hline Hook & $6.46(0.409)$ & $7.09(0.436)$ & 1.043 & 0.301 \\
\hline Rotor & $5.84(0.263)$ & $6.09(0.276)$ & 0.663 & 0.509 \\
\hline Connecting Rod & $5.42(0.245)$ & $5.79(0.301)$ & 0.963 & 0.339 \\
\hline Elbow connector & $5.25(0.436)$ & $6.41(0.197)$ & 2.787 & $0.008 *$ \\
\hline Hanger & $4.67(0.375)$ & $5.79(0.423)$ & 1.999 & $0.049 *$ \\
\hline T-Connector & $7.23(0.401)$ & $7.75(0.274)$ & 1.058 & 0.294 \\
\hline Box End Wrench & $6.54(0.244)$ & $7.20(0.265)$ & 1.846 & $0.069 * *$ \\
\hline Ball-Bearing Racer & $6.69(0.210)$ & $6.55(0.261)$ & -0.412 & 0.682 \\
\hline Castor Wheel & $6.04(0.275)$ & $5.71(0.317)$ & -0.780 & 0.438 \\
\hline Theory & $3.69(0.299)$ & $4.05(0.438)$ & 0.675 & 0.502 \\
\hline Applied Theory & $4.37(0.295)$ & $5.14(0.458)$ & 1.450 & 0.151 \\
\hline Average Exercises*** & $5.82(0.188)$ & $6.34(0.166)$ & 2.016 & $0.047 *$ \\
\hline $\begin{array}{l}* \text { Difference is significa } \\
* * \text { Difference is signific } \\
* * * \text { The score for "Theo }\end{array}$ & $\begin{array}{l}\text { at a level of } 0.05 \\
\text { at a level of } 0.1 \\
\text { is not considered in "Av }\end{array}$ & ge Exercises” & & \\
\hline
\end{tabular}

In a general assessment, it was observed that group $\mathrm{E}$ obtained better results than group $\mathrm{C}$ in all of the exercises and in applied theory, except in the "Ball bearing racer" and "Castor Wheel" exercises. Both of those exercises were completed at the end of the course and were not parts-based exercises, but assemblybased exercises, such that they brought in new variables that had not been controlled in the experiment.

It is worth highlighting the existence of a statistically significant difference at 95\% in favour of group E, in the "Elbow connector" and "Hanger" exercises. In the "Box End Wrench" exercise the difference was significant at $90 \%$ in favour of group E. The "Elbow connector" exercise was the first in which the student introduced alterations in the functional parameters and tested the importance of those changes. In this exercise, the results indicated that Group E obtained better scores of a significant nature at a confidence interval of $99 \%$.

Finally, the score achieved in "Average Exercises” showed that group E had better scores than group C at a statistically significant level of 95\%. This result provides global validation of the experimental methodology consisting in the introduction of summaries of the design intent rules and improved learning of 3D design. Although the averages were almost equal in some of the exercises in the two groups, the average of all the exercises (6.34 as against 5.83) was significantly higher in Group E than in Group C. 
Nevertheless, the scores obtained for the "Ball bearing racer" and the "Castor Wheel" exercises highlighted the need to improve the explanation of the design intent rules in assemblies.

\subsection{Second study (Design intent)}

In a similar way to the earlier study, in the first place, the sample was segmented according to some of the demographic data. In table 3 , the results of the segmentations are shown in the same way as table 1.

Also, in this case, the students with better spatial vision obtained better results in a significant way with regard to the variable "Total of Design Intent”. No significant differences were observed with regard to the other variables.

Table 3. Results for demographic segmentations with regard to “Total of Design Intent”

\begin{tabular}{|c|c|c|c|c|c|c|c|c|c|c|}
\hline \multicolumn{11}{|c|}{ Independent Samples Test } \\
\hline \multirow{2}{*}{ Variable } & \multirow{2}{*}{ Cut-off point } & \multicolumn{3}{|c|}{ Full sample (A-D) } & \multicolumn{3}{|c|}{ Group A (E-C) } & \multicolumn{3}{|c|}{ Group D (E-C) } \\
\hline & & Dif. & $\mathbf{t}$ & Sig. & Dif. & $t$ & Sig. & Dif. & $t$ & Sig. \\
\hline Spatial vision & $\mathrm{A}>60 \% ; \mathrm{D}<=60 \%$ & 2.30 & 1.978 & $0.052^{* *}$ & 3.08 & 2.317 & $0.025^{*}$ & 4.31 & 2.288 & $0.030^{*}$ \\
\hline TD marks & $A>6 ; D<=6$ & 1.52 & 0.998 & 0.321 & 0.16 & 0.042 & 0.967 & 3.90 & 3.385 & $0.001^{*}$ \\
\hline CAD Knowledge & $\mathrm{A}=$ Yes; $\mathrm{D}=\mathrm{No}$ & 1.05 & 0.837 & 0.405 & 4.89 & 2.503 & $0.021^{*}$ & 2.08 & 1.532 & 0.132 \\
\hline Gender & $\mathrm{A}=$ Male; $\mathrm{D}=$ Female & 0.43 & 0.281 & 0.780 & 3.12 & 2.471 & $0^{0.016}{ }^{*}$ & 3.72 & 1.364 & 0.200 \\
\hline
\end{tabular}

When considering the sample divided into the experimentation group and the control group and segmented by spatial vision, it may be affirmed that the students with greater spatial vision from group E obtained better results that were significant in comparison with those of students with greater spatial vision from group C. Also, the students with weaker spatial vision from group E obtained better results that were significant in comparison with the results of those from group $C$ (See table 3 ). The difference for the students with lower grades in TD was significant and in favour of group E.

With regard to the prior knowledge of CAD, there was a significant difference between the students from group $\mathrm{E}$, who had prior knowledge of $\mathrm{CAD}$, and those from group $\mathrm{C}$ under the same conditions. There was a significant difference for the variable gender between men in favour of group $\mathrm{E}$.

In second place, the same data from table 2 were contributed for each variable and experimental group (table 4). The distributions of the scores in "Skeletons", "Structures", "Features Name", and "Constraints", were not normal, but the distributions for both "Skeletons" and "Features Name" were not strongly asymmetrical, so the student t-test was considered valid. The non-parametric Wilcoxon test was used for "Structures" and "Constraints".

Table 4. Results of the design intent variables in the CAD exercises

\begin{tabular}{|c|c|c|c|c|c|}
\hline \multicolumn{6}{|c|}{ Independent Samples Test } \\
\hline \multirow{3}{*}{ Design Intent } & \multicolumn{2}{|c|}{ Experimental group or Control group } & \multicolumn{3}{|c|}{ Test for Equality } \\
\hline & C & $\mathbf{E}$ & \multirow[b]{2}{*}{ Name } & \multirow[b]{2}{*}{ Statistic } & \multirow[b]{2}{*}{ Sig. } \\
\hline & Mean (Std. Error Mean) & Mean (Std. Error Mean) & & & \\
\hline Skeletons & $3.71(0.382)$ & $4.94(0.357)$ & t-test & 2.321 & 0.023* \\
\hline Structures*** & $5.77(0.269)$ & $6.33(0.201)$ & Wilcoxon & -1.577 & 0.115 \\
\hline Features name & $1.85(0.098)$ & $1.99(0.100)$ & t-test & 0.919 & 0.361 \\
\hline Parts & $4.49(0.227)$ & $4.98(0.158)$ & t-test & 1.714 & $0.091 * *$ \\
\hline Alterations & $6.01(0.162)$ & $6.11(0.172)$ & t-test & 0.462 & 0.645 \\
\hline Constraints & $6.31(0.387)$ & $7.42(0.371)$ & Wilcoxon & -1.984 & $0.047 *$ \\
\hline Total of Design Intent & $21.80(0.807)$ & $24.81(0.751)$ & t-test & 2.701 & 0.009* \\
\hline \multicolumn{6}{|c|}{ * Difference was significant at a level of 0.05 . } \\
\hline$=$ Struct & & 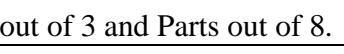 & & & \\
\hline
\end{tabular}


An initial general commentary is that a higher score was obtained in Group E for all of the design intent variables. In addition, the difference was statistically significant in "Skeletons" and "Constraints" at a confidence interval of 95\%. In the subsection "Parts", the difference was significant at 90\%.

Finally, Group E obtained a higher score than Group C in the sum of the four variables for "Total of Design Intent”, in a statistically significative way within the confidence interval of $99 \%$. This result once again validated the experimental methodology in use, from the point of view of design intent. The sum of the design intent variables (24.8 as against 21.8 ) was significantly higher in group E than in group C. The summaries were effective in the concepts relating to the creation of skeletons that included design intent, in the functional division in parts of the piece paying attention to the design process and in the geometric and dimensional constraints of the sketches. However, the summaries were not effective with regard to the alterations of the fundamental parameters of the models or the form of some of their parts and in the subsequent confirmations that the result is as expected. Improvements should be introduced that incorporate this concept at the start of the course and adding this concept to more exercises. For example, the "Rotor" and "Connecting Rod" exercises should not end with their modelling, but with the completion of the exercise after modifying their fundamental design parameters. By doing so, the students will establish whether their design strategy has been successful.

\section{CONCLUSIONS AND FUTURE WORK}

As various authors have pointed out, there is a need in industry for learning in relation to reuse and ease of alteration of the CAD models, to reduce the launch times for new products. As Jackson and Buxton (2007) affirmed, $48 \%$ of the CAD models are inflexible and fail after the introduction of alterations. The design intent concept should therefore be incorporated in learning that focuses on 3D design at University so that those designs are flexible and robust.

The learning of these concepts should be done using a methodology based on strategic knowledge (Mandorli and Otto 2013; Chester 2007). A learning methodology has been proposed, in which the different theoretical concepts of CAD and the training in the development of meta-cognitive skills are learnt through exercises, in which the design rules that are appropriate to each exercise are presented in the form of summaries.

It has been demonstrated that the design rules proposed by different authors and used in this investigation are effective for both experimental groups.

It may also be said that the proposed exercises are in general acceptable to learn the different design concepts (See table 2).

Besides, the inclusion of the summaries of the rules of design intent improve the learning of 3D design through exercises in a statistically significant way.

In general, the summaries completed from the point of view of design intent (Skeleton, Structure, Alterations and Sketch constraints) also improved the learning of 3D design in a statistically significant way. This improvement was especially noted in the concepts of creation of skeletons that included design intent, in the functional division into parts of the piece, paying attention to the design process, and in the sketch constraints.

From a demographic point of view, it has been confirmed that the students with stronger spatial vision, as may be expected, were better at preparing the CAD models. They also applied the design intent rules better. In tables 1 and 3, it may be seen that the results of the students in CAD improved in a significant way, both with regard to students with weaker and stronger spatial vision and students with prior knowledge of CAD and those with less knowledge of TD, if they used the summaries of the CAD rules.

The need was confirmed to continue investigating into two fundamental aspect-the first is that at the start of the course, the alterations of the CAD models should be incorporated as part of the learning of design intent, so that students have a clear idea from the outset of which of their 3D modelling strategies are the most appropriate. More exercises should also be completed where the students can include alterations to the functional geometric variables. The second is that the summaries of the rules on design intent for assemblies and mechanisms should be improved. 


\section{REFERENCES}

Alducin-Quintero, G., Rojo, A., Plata, F., Hernández, A., \& Contero, M. 3D model annotation as a tool for improving design intent communication: A case study on its impact in the engineering change process. In Proceedings of the ASME Design Engineering Technical Conference, 2012 (PARTS A AND B ed., Vol. 2, pp. 349-356). doi:10.1115/DETC2012-70872.

Ault, H. K. (1999). Using Geometric Constraints to Capture Design Intent. Journal for Geometry and Graphics, 3(1), 39-45.

Barbero, B. R., \& García, R. G. ( 2011). Strategic Learning of Simulation and Functional Analysis in the Design and Assembly of Mechanisms With CAD on a Professional Master's Degree Course. Computer Applications in Engineering Education, 19, 146-160, doi:10.1002/cae.20300.

Bi, Z. (2013). Teaching of Parametric Modeling Methodologies for Undergraduate Engineering Students. WSEAS Transaction on advances in engineering education, 10(1), 1-13.

Bodein, Y., Rose, B., \& Caillaud, E. (2013). A roadmap for parametric CAD efficiency in the automotive industry. Computer-Aided Design, 45(10), 1198-1214, doi:10.1016/j.cad.2013.05.006.

Bodein, Y., Rose, B., \& Caillaud, E. (2014). Explicit reference modeling methodology in parametric CAD system. Computers in Industry, 65(1), 136-147, doi:10.1016/j.compind.2013.08.004.

Burón Orjas, J. (1993). ENSENAR A APRENDER: Introducción a la metacognición [Teaching to learn: Introduction to metacognition]. Bilbao (España).

Camba, J., Contero, M., Michael, J., \& Company, P. (2014a). Extended 3D annotations as a new mechanism to explicitly communicate geometric design intent and increase CAD model reusability. Computer-Aided Design, 57, 61-73, doi:10.1016/j.cad.2014.07.001.

Camba, J., Cosin, A., \& Contero, M. An Evaluation of Formal Strategies to Create Stable and Reusable Parametric Feature-Based 3D Models. In ASME 2014 International Mechanical Engineering Congress and Exposition; Systems, Design, and Complexity, Montreal, Quebec, Canada, November 14-20 2014 b (Vol. 11, pp. 1-7). doi:10.1115/IMECE2014-37859.

CEEB (1939). Special Aptitude Test in Spatial Relations. USA: Developed by the College Entrance Examination Board.

Contero, M. (2015). Gestión de anotaciones 3D sobre modelos CAD para mejorar el proceso de diseño en ambientes industriales y arquitectónicos. http://www.labhuman.com/es/node/800. Accessed 15th. January 2015.

Córdova, F. (2009). Aprendizaje estratégico y metacognitivo. Un enfoque Cognitivo y constructivista [Strategic and metacognitive learning. A Cognitive and constructivist approach]. http://es.slideshare.net/alethias48/aprendizaje-estrategico-y-metacognitivo. Accessed 12th July 2014.

Chester, I. (2007). Teaching for CAD expertise. International Journal of Technology and Design Education, 17, 23-35, doi:10.1007/s10798-006-9015-z.

Drury, J. L., Pfaff, M. S., Klein, G. L., \& Liu, Y. (2013). Decision space visualization: lessons learned and design principles. Paper presented at the Proceedings of the 15th international conference on Human-Computer Interaction: interaction modalities and techniques - Volume Part IV, Las Vegas, NV,

Gebhard, R. (2013). A Resilient Modeling Strategy. Paper presented at the Solid Edge University 2013, Cincinnati, Ohio, June 24-27

Hartman, N. W. (2004). The Development of Expertise in the Use of Constraint-based CAD Tools: Examining Practicing Professionals. Engineering Design Graphics Journal, 68(2), 14-26.

Hartman, N. W. (2005). Defining Expertise in the Use of Constraint-based CAD Tools by Examining Practicing Professionals Engineering Design Graphics Journal, 69(1), 6-15.

Herrera, A., \& Marcelo, N. (2006). La Metacognición en la educación [Metacognition in education]. http://www.monografias.com/trabajos34/metacognicion-escuela/metacognicion-escuela.shtml. Accessed 5th. July 2014.

Iyer, G. R., \& Mills, J. J. (2006). Design Intent in 2D CAD: Definition and Survey. Computer-Aided Design and Applications, 3(1-4), 259-267, doi:10.1080/16864360.2006.10738463.

Jackson, C., \& Buxton, M. (2007). The Design Reuse Benchmark Report. Seizing the Opportunity to Shorten Product Development. (pp. 20). Boston: Aberdeen Group.

Kimura, F., \& Suzuki, H. (1989). A CAD System for Efficient Product Design Based on Design Intent. CIRP Annals - Manufacturing Technology, 38(1), 149-152, doi:10.1016/S0007-8506(07)626729. 
Mandorli, F., \& Otto, H. E. (2013). Negative Knowledge and a Novel Approach to Support MCAD Education. Computer-Aided Design and Applications, 10(6), 1007-1020, doi:10.3722/cadaps.2013.1007-1020

Otey, J., Company, P., Contero, M., \& Camba, J. (2014). A review of the design intent concept in the context of CAD model quality metrics. Paper presented at the 121st ASEE Annual Conference \& Exposition, Indianapolis, IN, June 15-18,

Rynne, A., \& Gaughran, W. ( 2008). Cognitive modeling strategies for optimum design intent in parametric modelling (PM). Computers in Education Journal, 18(1), 55-68.

Salehi, V., \& McMahon, C. Action research into the use of parametric associative CAD systems in an industrial context. In M. G. Norell Bergendahl, M.; Leifer, L.; Skogstad, P.; Lindemann, U. (Ed.), 17th International Conference on Engineering Design, Palo Alto, CA, USA, 24-27 August 2009a (Vol. 5, pp. 133-144)

Salehi, V., \& McMahon, C. Development of a generic integrated approach for parametric associative CAD systems. In M. G. Norell Bergendahl, M.; Leifer, L.; Skogstad, P.; Lindemann, U. (Ed.), ICED 09, the 17th International Conference on Engineering Design, Design Methods and Tools (pt. 1), Palo Alto, CA, USA, August 24-27 2009b (Vol. 5, pp. 145-156)

Salehi, V., \& McMahon, C. (2011). Development and application of an integrated approach for parametric associative CAD design in an industrial context. Computer-Aided Design and Applications, 8(2), 225-236, doi:10.3722/cadaps.2011.225-236.

Ugartetxea, J. (2001). Motivación y Metacognición, más que una realción [Motivation and Metacognition, more than a relationship]. Revista ELectrónica de Investigación y EValuación Educativa, 7(2_1),

Yang, J., \& Han, S. (2006). Repairing CAD model errors based on the design history. Computer-Aided Design, 38(6), 627-640, doi:10.1016/j.cad.2006.02.007.

Ye, X., Peng, W., Chen, Z., \& Cai, Y.-Y. (2004). Today's students, tomorrow's engineers: an industrial perspective on CAD education. Computer-Aided Design, 36(14), 1451-1460, doi:10.1016/j.cad.2003.11.006.

Zhang, Y., \& Luo, X. Design Intent Information Exchange of Feature-based CAD Models. In World Congress on Computer Science and Information Engineering, Los Angeles, CA, March 31-April 22009 (Vol. 3, pp. 11-15): IEEE. doi:DOI 10.1109/CSIE.2009.536. 